\title{
Pancreatitis Traumática
}

\author{
Dr. Eric Saelzer W. ${ }^{1}$; Dr. Gustavo Aldunate N. ${ }^{1}$; Dra. Isabel Almarza B. ${ }^{2}$; \\ Dra. Teresa Alarcón $0^{2}$.
}

\section{Traumatic Pancreatitis}

Two patients with traumatic pancreatitis are described. In both cases the injuries occured at accidents in bicycles. Their symptoms consisted in sudden abdominal pain, nausea, vomiting, low grade fever, pain at palpation of umbilical and epigastric areas, increased serum and urine amylase and abnormal pancreatic findings in the echotomographic studies. Patients were medically treated and in both cases coursed uneventfuly. The need of a careful history and the contribution of echotomography in this cases is stressed.

(Key words: Pancreatitis. Abdominal Trauma. Echotomographic diagnosis).

La pancreatitis traumática (PT) y los pseudo. quistes pancreáticos secundarios a traumatismos abdominales son entidades poco corrientes en el niño. Las referencias extranjeras al tema son poco frecuentes $5,8,9,10,12$ y en Chile encontramos sólo una ${ }^{4}$. Se cree que alrededor de $30 \%$ de las pancreatitis del niño son de orden traumático ${ }^{1}$. La oportunidad de observar dos casos en relación con ciertos típos de accidentes a que están hoy expuestos los niños, nos indujo a revisar el tema. Además de llamar la atención sobre un tipo específico de accidentes y sus posibles consecuencias, la descripción y análisis de los casos permite apreciar las dificultades que pueden existir para reconocer el problema $y$, al mismo tiempo describir diferentes modalidades de presentación y evolución de estas lesiones.

\section{Casos Clínicos}

1. KHV, preescolar de 3 años 8 meses. Sin antecedentes mórbidos, cayó de su bicicleta golpeándose el abdomen con el manubrio, después de lo cual presentó dolor progresivo en el sitio de la contusión, inapetencia, decaimiento y vómitos ocasionales, siendo hospitalizado al día siguiente. Al ingresar estaba en buenas condiciones de nutrición, tenia dolor fluctuante en la región

1. Clínica Alemana.

2. Unidad de Gastroentetología Infantil, Hospita! San Juar de Dios. umbilical. En el epigastrio se palpaba una masa dolorosa de límites irregulares que ocupaba la región epigástrica. En la piel se observaba pequeñas equimosis en la región para-umbilical izqujerda. Hemograma: Glóbulos Rojos (GR) 4.780.000; Hemoglobina (Hb) $12,3 \mathrm{~g} \%$, Hematocrito (Ht) $36,5 \%$, glóbulos blancos (GB) 14,900 , Basófjlos (B) 1; Baciliformes (Bac) 1; Segmentados (S) 95; Línfocitos (L) 2; Monocitos (M) 1: velocidad de sedimentación globular (VHS) 22 $\mathrm{mm} 1^{\text {a }}$ hora; Plaquetas $300.000 \times \mathrm{mm}^{3}$; Glicemia $63 \mathrm{mg} / \mathrm{dl}$; Calcemia $9,4 \mathrm{mg} / \mathrm{dl}$; Electrolitos plasmáticos: $\mathrm{Na}-136 \mathrm{mEq} / 1, \mathrm{~K}-4,2 \mathrm{mEq} / 1, \mathrm{Cl}-101$ $\mathrm{mEq} / \mathrm{l}$. Orina: sin proteina, contenía escasos glóbulos rojos frescos; Amilasemia: $390 \mathrm{U} / 1$ (n: 10-55); Amilasuria de 24 horas $3.420 \mathrm{U} / 1$ (n: 350). En las radiografías de tránsito digestivo habian alteraciones sugerentes de infiltraciones (hematomas) gastro-duodeno-yeyunales. En la Ecotomografía abdominal el hígado aparecía sin alteracinnes; páncreas de estructura anormal, con zonas anecogénicas y otras de ecogenicidad ma. yor, sugerentes de lesiones pancreáticas hemorrágicas recientes y áreas de aspecto licuado. No se observaron alteraciones de la vesícula biliar ni colecciones abdominales. Fue tratado con ayuno, hidratación parenteral y analgésicos (Dipirona), según el dolor, hasta el quinto día en que se inició realimentación progresiva por vía oral. El dolor disminuyó progresivamente, cesaron los vómitos de las primeras 24 horas, y mejoró su ànimo; la masa epigástrica se circunscribió a una tumoración redondeada que dejó de palparse 20 días después del accidente, el hemograma se 
normalizó en los dias siguientes: amilasemiáa y amilasuria siguieron clevadas hasta 35 dias después del traumatismo.

Los controles ecotomográficos a los 20 dias de evolución mostruban aún una imagen redondeada de $2,7 \mathrm{~cm}$. de diámctro en el espesor del cuerpo pantreatico. En controles posteriores se redujo do tamaño y desapareció 2 meses después del accidente. (Fig. 1 a. b y c).
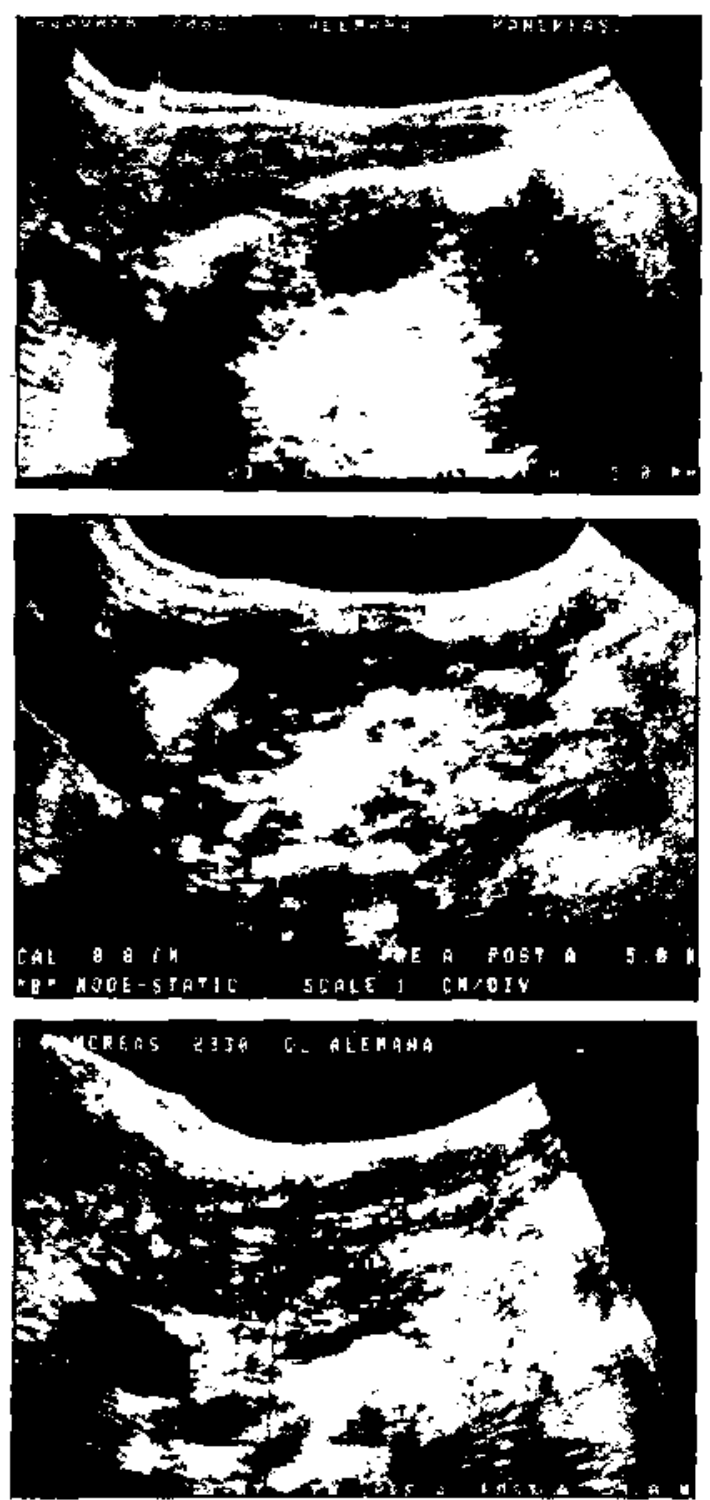

Figura 1, 21, b) $y$ c). Ityolución de las lesiones pancreáticas en el paciente. 1 , al inyresar (d), después do 20 dias (b) y 2 mescs (c).

2. ALM, niño de 6 años sin antecedentes patológicos de importancia. Bruscamente presen- to dolor ubdominal de tipo cólico referido a la regiön umbilical, agregándose decaimiento, inapetencia $y$ vómitos. Al segundo dia febril, $39^{\circ} \mathrm{C}$. dolor más intenso, encontrándose en el examen física, discreta resistencia muscular en la region subcostal derecha; tacto recial nomal. Hemograma GR 4.910.000: Hb. $14 \mathrm{~g} \%$; $\mathrm{Ht} \mathrm{42 \% ;} \mathrm{GB}$ 19.000 E O, Bac 1; S 70: L 20; M 9: Electrolitus séricos normales. Al tercer día estaba algo mojor pero al cuarto dia el dolor aumento de intensidad y se hizo permanente, agregindose anorexia. decaimicnto y fichre, En el cxamen abdominal habia signo de Blumberg positivo y en el tacto rectal. dolor a la palpacion digital del fondo de sico de Douglas: por lo que se decidió efectuar laparotomia exploradora que resultó nomal. Evoluciono bien hasta ol septime día del postoperaturio on que presentó fiebre escasi y dolor abdominal de tipo cólico, con leve sensibilidad en el hipocondrio izquierdo en la palpación del abdumen. Reinterrogada la madre acerea de sutecedentes de raumatismo, reiteró que no habiat sin embargo el nino. relató ahora haber usido la bicicleta de usa amjou el día del inicio de los sintomas, suftiendo ura caida en la que si golpeci el abdomen contra el manubrio. Despucs de iste antecedente sc encontraron cifras de Amitasemia de 1.800 U.I (n: $10-55)$ y Amilasuria 2025 LI. ett 24 horils (n: 600 a 6000 ) con estudio radiológico del tránsito intestinat y Foo. turnogratía abdomitnal nomales. El palciente foe tratidu cur reposo y analgésicos derivados de lit Dipironá siendo dado de alta des dias despotés completamente libre de sintomas.

\section{COMENTARIOS}

Los casus descritus liemen en comlin lis manifestaciones elinicus de comien/o consistem. tes en dulur abitominat de iniciacion bruscat, unorexid, nuiseds y/o vimitos, decainzento, alzat termita $y$ ur examen físico sugerente do un abdomen agudos quirúrigico

En el priner caso el claro antecedente do conrusion abdominal por caida de bicicteta fiacilitó al diagnóstico y la conducta médica pos. terior. La hipotesis diagnostica se contimo mediante mediciones de amilasa sérica y urinaria y la ecotomozrafía abdominal, que denost ró lesiones pancreaticas hemorrágicus recientes en la primera exploracion y la formacrion de un pseudoquiste veinte días después del accidente. En esti caso el tratamionto so hizo de acuerde con las normas para estos casos, con régimen de ayuno oral, hidratación, analgésicos. La realimentución fue lestamente progresiva desde el quinto dia de 
evolución mantectiéndose el réginacn hipograso hasta la normatización de la amilasemia. No flu necesario emplear antibióticos, transfinsiones, aljmositación parcnteral ni tratamientos quirúrgicos, en consideración a lia relativa benignidad de la lesión objetivada en fa evolución clínica $y$ el exaruen ecotomográlico seriado.

En el segundo caso, la falta inicial ac informacion sobre el tramatismo, y los sintomas do abdomere agudo que presentaba el enfermo impidicren el dianóstico opnrturto, el que sin embargo. fue confirmado posteriormente por nuevos aniecodentes $y$ niveles anomales de atrnilasa en stuer: y oristä.

Las pancreatitis som afeciones poco frecuen. tes en los niños de nuestro nedio ${ }^{2}, 3$ y más raras aun las de origen traumatico ${ }^{4}$.

Dentro le las puncreatitis esalumáticas. las producidas por cádas en bicicleta, difieren de olras cue tienen rejación con lesiones exteusis, resultado de accidentes a debidas a objetcs contundentes que getoratmeme lesionan tambist otros órganos.

El diagnóstico puede ser difícil. Desde luego que por su baja frecuencia, la ausencia de síntomas lípicos y a menudo del antecedente de tratumatismo previo, como sucedió, en uno de iruestros casos

Las tesiones producidas por el extremo del manubrio se caracterizan por su pequeīa superficie y la ausencia de marcas en la piel, si el objeto contundente es romo.

El compromiso del páncreass es de magnitud variable, limitado sólo a edema, y atdiferentes grados de inflamación, hemorragia circunscrita o difusa, waso en que pueden originarse pseudoquis. tes $y$, cuando la gravedad es nayor, rotura del brgaso.

Diversos autores senalan qte es frecuente qut exjsta un intervato libre de síntonas entre el momento del accidente $y$ el comienzo de las molestias, que va de días a semanas y por lo gencral de 1 a 7 dias $^{2}, 6$. En Jos adultos sc han descitu períodos de dos y más meses ${ }^{6}$ antes de que el pseudoquiste se hagil evidente por asociarse con otro trastorno, gastrodundenal o de otra indole 5 .

Los sintomas son poco característicos, los de origen aldominal son inespecíficos y a veces, como en ol caso 2, simulan un abdomen agudo induciendo a la exploración quirúrgica. A menudo la lesión no es correctamente identificada, aún en la laparotomía exploradora. La insuficiencia circulatoria(shock), citada frecuentemente en la literatura más antigua ${ }^{12}$ es rara de observvar.
La existencia de molestias abduminales vagas que se eltcuentran dentro de las síncmas descri. tos, obliga a ser cxtremadamente aclucioso en ta indagución de antecedentes de traumatismos previos $y$ en casos dudosus a reajizar exámenes específicos como lo son las determinaciones de amilasa sn suero y urina (especialmente seriados) y la contomografía.

Hasta lace algunos años se consideraba que la curación espontánea de las pancreatitis era excepciunal, por ello el tratamiento era casi siempre quirúrgico ${ }^{3}, 4,5,8$. Este concepto se veŕa reforzado por el heclio que en algunas series el diagnóstico se confirmaba en casi la mitad de los casos en la laparotomiald.

La introducción de la ecotomografía (ET) y otros métodos diagnósticos por inágenes (1omografia computarizida, angingrafía, etc.), at permilir evalualr con gran precision la magnitud $y$ caracteristicas de la lesión, han permitido adoptar conductas más conservadoras.

Lil Ecotomugralfia ha encontrido gran aplicacion en el estudio de las lesiones pancreáticas del nifro por el escaso contenido de grasa intrabalominal y retroperitoneal en relación al adulto. El procediniento constifuye hoy un metodo de cleccion para el diagnóstico y cuntrol de la crolución de los pseudoquistes pancreáticos, remmplazando a los estudios radiológicos?. Con tendicas corrientes la ET permite identificar quisces de hasta un cm. de diámetro. El método liene además la ventaja de su cjecución simple, menor costo y escaso riesgo, pues no requiere el uso de radiofámacos ${ }^{7}$. El tratamiento no es orientado por el tamano del pseudoquiste, pues quuistes de más de $10 \mathrm{~cm}$. de diámetro tienden a reabsorberse sin problemas, generalmente en plazos de 263 meses 9

Según Weitzel ${ }^{9}$ la intervención quirúrgica deheria ser indicada con urgencia en casos con hemorragia y rotura del pánereas, formación de abeesos, aparición de ictericia obstructiva o ileo. En otris situaciones se planter la intervención después de algunos meses de evolución, si persisten los sintomas o no se observa reducción de pseudoquistes de gran tamaño. Cuando es necesa. rio realizar una exploración quirúrgica, es prefe. rible intervenir una vez que haya disminuido el componente inflamatorio que caracteriza la evolución de las primeras etapas de la afección. A pesar del frecuente retardo con que se hace el diagnóstico los nuevos metodos de estudio y las posibilidades de instifuir un tratamiento médico conservador, ha contribuido notoriamente a mejorar el pronóstico de esta lesión. 


\section{RESUMEN}

Se describen dos casos de pancreatitis traumática asociada a accidentes en bicicleta. En ambos pacientes los síntomas consistieron en dolor abdominal de comienzo brusco, náuseas. vómitos, fiebre, dolor en la palpación del epigastrio y la zona umbilical, La evidencia de pancreatitis se obtuvo del aumento de la concentración sérica y urinaria de amilasa y de las aiteraciones detectadas en la ecotomografía abdominal que en un caso demostró lesiones sugerentes de hemorragias pancreáticas y en otro, con mayor tiempo de evolución, la formación de un pseudoquiste. Ambos pacientes evolucionaron satisfactoriamente con un manejo conservador.

\section{REFERENCIAS}

1. Roy, C., Silverman, A., Cozzeto, F.: Pejiatric

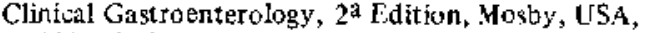
p. 641,1975 .
2. Jaeger, H.: Pancreatitis Aguda Hemorrágica en el Niño. Rev. Chil. Pediatr. 14:18, 1943.

3. Ossandón, E. del Río, A.: Pancreatitis Aguda no Traumática. Rev. Chil. Pediatr. 45: 446, 1974.

4. Aldunate, $G$., Cifuentes, A.; Foradori, $C .:$ Lesiones traumáticas del páncreas en el niño. Rev. Chil. de Pediatı. 40: 100, 1969.

5. Ravitch, M.: The Pancreas in Infants an Children Surg Clin. Amer, 55: 377, 1975.

6. Pedinielli, $L$., Marinetti $C$., et Felix M.: Pancreatities sigués et pseudo-kystes post-tralumatiques du pancreas. A propos de 12 observations. J. Chir., 116: 97,1979 .

7. Fonkuchen, E.: Current Concepts in Pancreatic Imaging. Surg. Ciin. Amir., 17: 61, 1981.

8. Grasfeld, J., Cooney.: Pancreatic and Gastrointestinal Tratma in Cliddren. Pediatr Clen. North. Am. 22: 363,1975 .

9. Weitzel, D., Weiss, H. Troger, J.; Hofmann, S.; Schul, $R$.: Besonderhciten der posturaumatischen Pankreas-Pseudocyst im Kindesalter. Mschr Kinderheilk, k28: 330, 1980.

10. Stone, H.: Pancreatic and Duodenal trauma in Clijldren J. Pediatr. Surg. 7: 670, 1972

11. Cooney et al: cit. P. 8.

12. Schega, W. Dennhardt, D.: Pankreasverletzungen in Kindersalter Dtscll Med. Wschr. 43: 96, 1971. 